\title{
Indução de tolerância à murcha bacteriana em híbridos de tomates por aplicação de giberelina
}

\author{
Induction of tolerance to bacterial wilt in hybrids of tomatoes by application of gibberellin
}

\author{
Fabrício Rodrigues ${ }^{1 \star}$, Ana Carolina Pacheco Nunes ${ }^{2}$, Daniel Diego Costa Carvalho ${ }^{1} \&$ Mylla \\ Crysthyan Ribeiro ${ }^{3}$
}

\footnotetext{
${ }^{1}$ Universidade Estadual de Goiás, Ipameri, GO, Brasil. Autor para correspondência: fabricio.rodrigues@ueg.br.

2 Instituto Federal Goiano, Rio Verde, GO, Brasil.

${ }^{3}$ Universidade Federal de Goiás, Goiânia, GO, Brasil.
}

Submissão: 17/03/2017 / Aceite: 30/10/2017

\begin{abstract}
RESUMO
A murcha-bacteriana (Ralstonia solanacearum) é um sério problema para a produção de solanáceas em diversas regiões brasileiras, principalmente, sob ambientes protegidos. A giberelina $\left(\mathrm{GA}_{3}\right)$ é um hormônio que tem sua eficiência comprovada para o aumento de diversas características em plantas de tomate, porém não há estudo a respeito do potencial desse hormônio para a indução de tolerância à doença. Assim, o objetivo deste trabalho foi estudar o efeito da aplicação de giberelina para aumentar a tolerância em híbridos de tomate à murcha bacteriana. O delineamento experimental utilizado foi o de blocos casualizados, em esquema fatorial $8 \times 5$ (híbridos e épocas de aplicação), com três repetições. Foram estudadas as variáveis de altura de planta, número de flores, diâmetro transversal dos frutos, massa fresca da parte aérea, número de frutos e peso dos frutos após 120 dias do plantio. Verificou-se que existe diferença significativa para todas as variáveis estudadas e, também, para as fontes de variação. A giberelina é capaz de induzir aumento da tolerância em plantas de tomate à murcha-bacteriana, entretanto a época de aplicação depende do híbrido e da variável desejada para se obter o melhor desempenho. A aplicação feita no $24^{\circ}$ dia, após o plantio, foi a que mais apresentou ganhos elevados nos diferentes híbridos e variáveis, seguido do $32^{\circ}$ dia.
\end{abstract}

PALAVRAS-CHAVE: Solanum lycopersicum L., Ralstonia solanacearum, hormônio, frutos.

\begin{abstract}
The bacterial wilt (Ralstonia solanacearum) is a serious problem to produce Solanaceae plants in several Brazilian regions, mainly under protected environments. The gibberellin $\left(G A_{3}\right)$ is a hormone that has its proven efficiency to increase several traits in tomato plants, however, there is no study about the potential of this hormone for the induction of disease tolerance. Thus, the objective of the work was to study the effect of the application of gibberellin to increase tolerance in tomato hybrids to bacterial wilt. The experimental design was a randomized block design, in a factorial scheme $8 \times 5$ (hybrids and application times), with three replications. The variables of plant height, number of flowers, fresh shoot mass, transverse diameter of fruits, number of fruits and fruit weight were studied after 120 days of sowed. It was verified that there is significant difference for all variables studied and for the sources of variation. The gibberellin can induce increased tolerance in tomato plants to bacterial wilt, however, the time of application is dependent on the hybrid and the desired variable to obtain the best performance. The application on the 24th day, after planting, was the one that presented the high gains in the different hybrids and variables, followed by the 32nd day.
\end{abstract}

KEYWORDS: Solanum lycopersicum L., Ralstonia solanacearum, hormone, fruits.

\section{INTRODUÇÃO}

O tomate (Solanum lycopersicum L.) possui importância social e econômica elevada no Brasil e no mundo, sendo a segunda espécie de maior importância entre as solanáceas. Segundo o Levantamento Sistemático da Produção Agrícola realizado pelo IBGE (2016), a produção brasileira de tomate, na safra 2015, foi de 4.145 milhões de toneladas, em uma área 62 mil hectares. 
Nas regiões Sul e Sudeste do Brasil, a cultura teve grande expansão sob cultivos protegidos, todavia, devido à dificuldade de se realizar rotação de cultura, por causa do manejo adotado e por questões econômicas (LOPES et al. 2015), o tomateiro necessita de maior atenção dos agricultores com relação às doenças. $O$ ambiente protegido possui elevada temperatura e umidade relativa, 0 que favorece 0 surgimento de diferentes patógenos. Entre as doenças que afetam a cultura do tomateiro, as de etiologia bacteriana estão entre as que mais causam prejuízos (ROCHA \& MOURA 2013).

No Brasil, a murcha-bacteriana (Ralstonia solanacearum Smith) é um fator de risco para a produção de solanáceas em diversas regiões brasileiras, a bactéria é adaptada a um elevado número de hospedeiros, sob as mais variadas condições, cosmopolita e extremante variável (TAKATSU \& LOPES 1997), sendo considerada a responsável pelo declínio em diversas culturas, como batata, tomate, pimentão e banana (MORAIS et al. 2015). Este patógeno está entre os mais difíceis de controlar e a eficiência das práticas atuais está na combinação de métodos de controle (químicos e biológicos) e nas práticas culturais (AYANA \& FININSA 2016), inclusive, com o uso de porta-enxertos (LOPES \& MENDONÇA 2016).

A murcha-bacteriana infecta as raízes das plantas por meio de aberturas, invadindo os vasos do xilema, logo após, ocorre a proliferação por todo o sistema vascular, secretando grandes quantidades de polissacarídeos extracelulares que impendem o transporte de água, podendo causar até a morte da planta (JIANG et al. 2014).

Com o intuito de melhorar o desempenho dos sistemas produtivos e atender à demanda do mercado de alimentos, existe a necessidade de aperfeiçoar e utilizar novas tecnologias no cultivo do tomate (SOUZA et al. 2015). Além disso, a utilização de fitorreguladores para o aumento de produtividade e, também, para qualidade de frutos tem sido estudada e confirmada em alguns trabalhos (FARINHA 2008), sendo as giberelinas os mais empregados.

Segundo resultados obtidos, MARTÍNEZ et al. (2013) relataram que a aplicação de giberelina, principalmente, com concentrações elevadas, variando de 4.000 a $10.000 \mathrm{\mu g} \mathrm{L}^{-1}$, aumentou a altura das plantas, comprimento das folhas, número das folhas, diâmetro do caule, massa fresca da plântula e da raiz e o volume radicular, com aplicações frequentes, sendo estas realizadas a cada 120 horas, após a formação das folhas verdadeiras. AYUB \& RESENDE (2010) estudaram concentrações variando de 0 a 120 ppm, aplicadas quando os frutos do segundo cacho apresentavam $10 \mathrm{~mm}$ de diâmetro, e detectaram aumento para massa fresca dos frutos, comprimento e diâmetro dos frutos.

Assim, a aplicação de giberelina exógena promove uma série de benefícios para as plantas de tomate e para o aumento dos frutos e da sua qualidade. Entretanto o estudo do efeito da giberelina para as plantas relacionado ao aumento da tolerância à murcha bacteriana com a aplicação, ainda, não foi analisado. Dessa forma, o objetivo deste trabalho foi estudar o efeito da aplicação de giberelina para o aumento da tolerância à murcha bacteriana em híbridos de tomate.

\section{MATERIAL E MÉTODOS}

O experimento foi conduzido na fazenda experimental da Universidade Estadual de Goiás (UEG), Campus Ipameri, em casa de vegetação, não climatizada e telada com sombrite $30 \%$, durante os meses de julho a setembro de 2014.

Os híbridos de tomate industriais utilizados foram o Acangatã, BRS Sena, H9553, HMX 7885, Caline Ipa-6, Saray, U-2006, UG 8169 F1, todos suscetíveis à murcha bacteriana.

$O$ delineamento experimental utilizado foi 0 de blocos casualizados, em esquema fatorial $8 \times 5$ (híbridos e épocas de aplicação), com três repetições, sendo a unidade experimental um vaso (12 L) contendo uma planta.

Os vasos foram preenchidos com solo de cerrado, da camada subsuperficial, classificado como Latossolo Vermelho distrófico, com pH - 4,9; Matéria orgânica - 24,1 g dm${ }^{-3} ; \mathrm{P}-5 \mathrm{mg} \mathrm{dm}^{-3} ; \mathrm{H}+\mathrm{Al}-30,3$ mmolc $\mathrm{dm}^{-3} ; \mathrm{K}-4,1 \mathrm{mmol}_{\mathrm{c}} \mathrm{dm}^{-3} ; \mathrm{Ca}-18,2 \mathrm{mmol}_{\mathrm{c}} \mathrm{dm}^{-3} ; \mathrm{Mg}^{-7,5} \mathrm{mmol}_{\mathrm{c}} \mathrm{dm}^{-3}$; SB - 27,8 mmolc $\mathrm{dm}^{-3}$; CTC $57,6 \mathrm{mmol}_{\mathrm{c}} \mathrm{dm}^{-3}$; V\% - 47,7. O solo foi tratado com 3,5 g de calcário dolomítico (PRNT 70\%) para cada quilo de solo, aplicados 40 dias antes da semeadura. Logo após, foram aplicadas $4,8 \mathrm{~g}$ de superfosfato simples, $1,3 \mathrm{~g}$ de cloreto de potássio, $1,0 \mathrm{~g}$ de ureia na semeadura e $0,75 \mathrm{~g}$ após 30 dias.

Foram semeadas seis sementes por vaso e, após 10 dias, fez-se o desbaste, permanecendo apenas uma planta e, também, a inoculação da Ralstonia solanacearum, sendo esta bactéria isolada de experimentos de campo, da área experimental da UEG, identificada mediante diagnose baseada em sintomatologia e pelo teste de exsudação de células bacterianas. Para a aplicação, foi utilizada uma

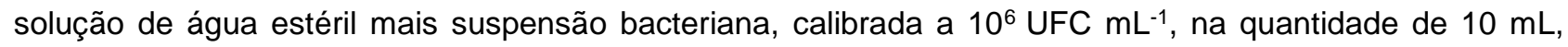


pulverizada sob o solo, em cada parcela, com exceção do controle (ausência de murcha e sem aplicação de giberelina). A reação da planta foi avaliada pelo comportamento após a inoculação, por meio dos sintomas característicos e pelo teste do copo (LOPES \& ÁVILA 2005).

A irrigação foi feita com $500 \mathrm{ml}$ de água a cada dois dias, permanecendo com a capacidade de campo em torno de $70 \%$. As aplicações de giberelina $\left(\mathrm{C}_{19} \mathrm{H}_{22} \mathrm{O}_{6}\right)$, também, denominada de $\mathrm{GA}_{3}$, ocorreram no $8^{\circ}, 16^{\circ}, 24^{\circ}$ e $32^{\circ}$ dia após o plantio, na concentração de $100 \mathrm{mg} \mathrm{L}^{-1}$, similar à dose recomendada por AYUB \& REZENDE (2010), pulverizadas através de uma bomba manual, com capacidade de armazenamento de 5 litros. Para pulverização da giberelina, os vasos foram retirados da estufa e a aplicação deu-se no sentido de cima para baixo até molhar todas as folhas.

Foram avaliadas, aos 120 dias após o plantio, as variáveis de altura de planta - medida referente do colo da planta ao ápice da haste principal, mensuração feita com régua graduada em centímetros $(\mathrm{cm})$; número de flores - número total de flores totalmente abertas, em todo o período de desenvolvimento até a avaliação, em unidade (un.); diâmetro transversal dos frutos - valor referente à média obtida na parcela, com base no valor de todos os frutos, utilizando-se um paquímetro digital na parte mediana do fruto, em milímetros $(\mathrm{mm})$; massa fresca da parte aérea - valor referente ao peso fresco da planta, sem os frutos e raiz, em gramas $(\mathrm{g})$; número de frutos - número total de frutos de cada parcela, incluindo frutos maduros e verdes, em unidade (un.); peso dos frutos - valor referente ao peso médio dos frutos maduros de cada parcela, em gramas (g).

A normalidade residual foi verificada pelo teste de Shapiro-Wilk, e o teste de Bartlett foi utilizado para verificar a homocedasticidade residual. Posteriormente, os dados experimentais foram submetidos à análise de variância pelo teste $\mathrm{F}$ e, quando significativo, as médias compradas pelo teste de Scott- Knott a $5 \%$ de probabilidade, no programa computacional SISVAR 5.3 (FERREIRA 2011).

\section{RESULTADOS E DISCUSSÃO}

Observa-se, na Tabela 1, que houve diferença significativa para todas as fontes de variação e para a interação cultivar e época de aplicação, demonstrando que os cultivares apresentaram comportamentos divergentes para as diferentes variáveis e que a época de aplicação da $\mathrm{GA}_{3}$, também, interferiu nas características em estudo, além de suas interações.

Tabela 1. Quadrado médio das variáveis altura de planta (ALT), número de flores (NFLO), massa fresca da parte aérea (MFPA), diâmetro transversal dos frutos (DIAM), número de frutos por planta (NFR) e peso dos frutos (PFR) em diferentes épocas de aplicação de giberelina, em híbridos de tomate.

Table 1. Mean square of the plant height (ALT), number of flowers (NFLO), fresh shoot mass (MFPA), transverse diameter of fruits (DIAM), number of fruits per plant (NFR) and fruit weight (PFR), at different times of application of gibberellin, in tomato hybrids.

\begin{tabular}{lccccccc}
\hline F.V. & GL & ALT & NFLO & MFPA & DIAM & NFR & PFR \\
\hline Cultivar (C) & 7 & $83,36^{* *}$ & $84,83^{* *}$ & $585,96^{* *}$ & $1,45^{* *}$ & $32,62^{* *}$ & $1863,66^{* *}$ \\
Época (E) & 4 & $12,41^{* *}$ & $208,65^{* *}$ & $710,83^{* *}$ & $10,39^{* *}$ & $22,37^{* *}$ & $2697,74^{* *}$ \\
C x E & 28 & $20,30^{* *}$ & $112,43^{* *}$ & $629,58^{* *}$ & $2,80^{* *}$ & $5,20^{* *}$ & $411,93^{* *}$ \\
Bloco & 2 & 0,21 & 0,92 & 24,88 & 0,04 & 0,52 & 21,82 \\
Erro & 78 & 0,54 & 2,19 & 17,41 & 0,08 & 0,32 & 12,02 \\
\hline CV (\%) & & 2,43 & 6,79 & 5,95 & 3,98 & 3,98 & 8,70 \\
\hline
\end{tabular}

${ }^{*} \mathrm{e}^{\star \star}$ - significativo a 5 e $1 \%$ de probabilidade pelo teste $\mathrm{F} ; \mathrm{CV}(\%)$ - coeficiente de variação.

A inoculação foi eficiente, pois todas as parcelas que foram infectadas evidenciaram sintomas de murcha no período experimental, sendo que, para estimular a infecção por Ralstonia solanacearum, os solos permaneceram com volume de água elevado ( $70 \%$ da capacidade de campo), além da alta temperatura da estufa, que variou de 20 a $35^{\circ} \mathrm{C}$, ideais para o desenvolvimento da doença.

Detecta-se que o híbrido Caline Ipa 6 apresentou melhor desempenho para altura de plantas, seguido do Acangatã e H9553, com médias superiores a $32 \mathrm{~cm}$ no tratamento controle (Tabela 2). Todavia apresentaram desempenho inferior ou similar com a aplicação de giberelina, independente da época de aplicação, em comparação ao controle. O comportamento observado nos demais híbridos convergem com CATO et al. (2013) e TAIZ \& ZEIGER (2013), que relatam que a aplicação exógena de giberelina promove o alongamento dos entrenós e, associado a esse efeito, também, existe a redução na espessura do caule e 
no tamanho da folha, além da coloração verde-clara das folhas, similar ao observado nos híbridos durante a condução experimental.

Tabela 2. Valores médios de altura de planta, número de flores e massa fresca da parte aérea, com aplicação de giberelina em diferentes épocas de desenvolvimento (0, 8, 16, 24 e 32ํำ dias), em híbridos de tomate.

Table 2. Mean values of plant height, number of flowers and fresh shoot mass, with gibberellin application at different developmental stages $\left(0,8,16,24\right.$ and $32^{\circ}$ days) in tomato hybrids.

\begin{tabular}{|c|c|c|c|c|c|}
\hline & \multicolumn{5}{|c|}{ Altura de Planta $(\mathrm{cm})$} \\
\hline Cultivares & 0 & $8^{\circ}$ & $16^{\circ}$ & $24^{\circ}$ & $32^{\circ}$ \\
\hline Acangatã & $33,17 \mathrm{bA}$ & $32,33 \mathrm{bA}$ & $29,84 \mathrm{cB}$ & $32,00 \mathrm{bA}$ & $29,34 \mathrm{~dB}$ \\
\hline BRS Sena & $32,00 \mathrm{cB}$ & $33,00 \mathrm{aB}$ & $31,84 \mathrm{bB}$ & $35,84 a A$ & $34,67 a A$ \\
\hline H9553 & $32,84 \mathrm{bA}$ & $31,67 \mathrm{cA}$ & $30,34 c B$ & $31,67 \mathrm{bA}$ & $30,84 \mathrm{cB}$ \\
\hline HMX 7885 & $26,17 \mathrm{eC}$ & $28,17 \mathrm{eB}$ & $30,50 \mathrm{cA}$ & $29,00 \mathrm{cB}$ & $28,17 \mathrm{eB}$ \\
\hline Caline IPA-6 & $36,17 a A$ & $30,84 \mathrm{cB}$ & $30,50 \mathrm{cB}$ & $28,17 \mathrm{cC}$ & $24,00 \mathrm{gD}$ \\
\hline SARAY & $19,17 \mathrm{fC}$ & $28,34 \mathrm{eA}$ & $27,50 \mathrm{~dB}$ & $29,17 \mathrm{cA}$ & $27,50 \mathrm{eB}$ \\
\hline U2006 & $29,17 \mathrm{~dB}$ & $30,67 \mathrm{cA}$ & $27,50 \mathrm{dC}$ & $28,34 \mathrm{cB}$ & $25,67 f D$ \\
\hline UG 8169 F1 & $30,84 \mathrm{cC}$ & $30,00 \mathrm{dC}$ & $34,17 \mathrm{aA}$ & $33,00 \mathrm{bB}$ & $32,17 \mathrm{bB}$ \\
\hline \multirow[t]{2}{*}{ Média } & 29,94 & 30,63 & 30,27 & 30,90 & 29,05 \\
\hline & \multicolumn{5}{|c|}{ Número de flores (un.) } \\
\hline Cultivares & 0 & $8^{\circ}$ & $16^{\circ}$ & $24^{\circ}$ & $32^{\circ}$ \\
\hline Acangatã & $21,33 a B$ & $27,67 a A$ & $21,00 \mathrm{cB}$ & $23,67 \mathrm{bB}$ & $22,00 \mathrm{bB}$ \\
\hline BRS Sena & $17,33 \mathrm{bC}$ & $26,33 \mathrm{aB}$ & $17,33 d C$ & $35,67 a A$ & $37,67 a A$ \\
\hline H9553 & $24,00 \mathrm{aB}$ & $22,67 \mathrm{bB}$ & $27,67 \mathrm{bA}$ & $23,33 b B$ & $15,00 \mathrm{dC}$ \\
\hline HMX 7885 & $21,00 \mathrm{aB}$ & $21,67 \mathrm{cB}$ & $21,00 \mathrm{cB}$ & $25,67 \mathrm{bA}$ & $14,67 \mathrm{dC}$ \\
\hline Caline IPA-6 & $22,33 a A$ & $21,00 \mathrm{cA}$ & $15,67 \mathrm{~dB}$ & $22,33 \mathrm{bA}$ & $18,00 \mathrm{cB}$ \\
\hline SARAY & $9,00 \mathrm{dE}$ & $24,00 \mathrm{bB}$ & $32,00 a A$ & $17,33 c D$ & $20,67 b C$ \\
\hline U2006 & $13,67 \mathrm{cC}$ & $17,00 \mathrm{~dB}$ & $19,00 \mathrm{cB}$ & $36,00 \mathrm{aA}$ & $12,67 \mathrm{dC}$ \\
\hline UG 8169 F1 & $14,67 \mathrm{cD}$ & $17,33 \mathrm{dC}$ & $26,67 \mathrm{bA}$ & $23,33 b B$ & $22,33 \mathrm{bB}$ \\
\hline \multirow[t]{2}{*}{ Média } & 17,92 & 22,21 & 22,54 & 25,92 & 20,38 \\
\hline & \multicolumn{5}{|c|}{ Massa fresca da parte aérea $(\mathrm{g})$} \\
\hline Cultivares & 0 & $8^{\circ}$ & $16^{\circ}$ & $24^{\circ}$ & $32^{\circ}$ \\
\hline Acangatã & $77,22 \mathrm{bA}$ & $78,27 \mathrm{bA}$ & $68,57 \mathrm{~dB}$ & $71,46 \mathrm{cB}$ & $72,73 \mathrm{bB}$ \\
\hline BRS Sena & $65,67 \mathrm{cC}$ & $102,42 a A$ & $63,43 \mathrm{dC}$ & $81,79 \mathrm{bB}$ & $84,52 \mathrm{aB}$ \\
\hline H9553 & $68,77 \mathrm{cB}$ & $59,10 \mathrm{cC}$ & $77,06 \mathrm{cA}$ & $66,19 \mathrm{~dB}$ & $54,00 \mathrm{cC}$ \\
\hline HMX 7885 & $58,34 \mathrm{~dB}$ & $69,87 \mathrm{bA}$ & $69,24 d A$ & $74,44 \mathrm{cA}$ & $69,62 \mathrm{bA}$ \\
\hline Caline IPA 6 & $97,40 a A$ & $59,14 c D$ & $70,04 \mathrm{dC}$ & $77,46 \mathrm{cB}$ & $53,10 \mathrm{cD}$ \\
\hline SARAY & $23,50 \mathrm{fC}$ & $73,71 \mathrm{bB}$ & $91,73 a A$ & $74,27 \mathrm{cB}$ & $76,00 \mathrm{bB}$ \\
\hline U2006 & $44,73 \mathrm{eC}$ & $59,44 c B$ & $55,14 \mathrm{eB}$ & $81,95 \mathrm{bA}$ & $56,79 \mathrm{cB}$ \\
\hline UG 8169 F1 & $68,74 c C$ & $60,17 \mathrm{cD}$ & $84,60 \mathrm{bB}$ & $92,08 a A$ & $70,10 b C$ \\
\hline Média & 63.05 & 70.26 & 72,48 & 5 & 67.11 \\
\hline
\end{tabular}

Médias seguidas pela mestra na vertical, minúscula nas colunas e maiúscula nas linhas, não diferem entre si pelo teste de Scott-Knott (5\%).

O híbrido BRS Sena passa a apresentar melhor desempenho, com incrementos médios de $4,1 \mathrm{~cm}$, com aplicações no $8^{\circ}, 2^{\circ}$ e $32^{\circ}$ dia, com isso, demonstrando que o híbrido revela maior capacidade de retardar o efeito da infecção e promover o crescimento e desenvolvimento da planta com a aplicação. Segundo RODRIGUES et al. (2011), as raças de $R$. solanacearum exercem agressividades distintas a depender do hospedeiro, variação observada nos híbridos avaliados. Além disso, a gama de plantas que pode servir de inoculo é muito ampla, variando de plantas cultivadas a ornamentais (aproximadamente 200 espécies vegetais), ressaltando, assim, a sua variabilidade patogênica e a diferença nos danos observados. 
Observa-se que o híbrido BRS Sena, para a variável número de flores, foi o que apontou o maior incremento com a aplicação de $\mathrm{GA}_{3}$, aproximadamente 37 flores, com a aplicação no $24^{\circ}$ e $32^{\circ}$ dia (Tabela 2). O valor obtido por esse híbrido no tratamento controle foi de 17,3 flores por planta, porém, com as aplicações ao $24^{\circ}$ e $32^{\circ}$ dia, o híbrido assinalou um incremento de aproximadamente 19 flores a mais que o controle na ausência da murcha bacteriana. O híbrido U-2006 apresentou comportamento similar ao BRS Sena, com aplicação no $24^{\circ}$ dia, sendo seu efeito muito mais expressivo se comparado a outras aplicações, sendo o valor 2,6 vezes maior que o controle. É importante salientar que o desempenho e os valores observados foram dependentes da época de aplicação, do híbrido e da interação patógeno x hospedeiro, que para os híbridos Acangatã, $\mathrm{H} 9553$ e HMX 7885, os de melhor desempenho no controle, obtiveram maior número de flores no $8^{\circ}, 16^{\circ}$ e no $24^{\circ}$ dia, respectivamente.

A massa fresca da parte aérea apresentou incremento com a aplicação de $\mathrm{GA}$ 3 para a maioria dos híbridos de tomate testados, com exceção dos híbridos Acangatã, que, com a aplicação, teve o mesmo desempenho do controle ou reduziu a sua massa com a aplicação, e o Caline Ipa-6, que reduziu em até $42,4 \%$ da sua massa com a aplicação no $8^{\circ}$ e $32^{\circ}$ dia (Tabela 2 ). Resultados divergentes foram obtidos por VENDRUSCOLO et al. (2016), que demonstraram que a aplicação de giberelina na semente, com concentrações variando de 0 a $2,5 \mathrm{mg} \mathrm{L}^{-1}$, tem comportamento quadrático e com baixo efeito sobre a fitomassa seca da parte aérea, não apresentando tal variação ou mesmo ganhos elevados na massa como os observados nesta pesquisa. Segundo CATO et al. (2013), a giberelina na concentração de 5 mg $\mathrm{L}^{-1}$, aplicada três vezes durante a fase vegetativa e duas vezes na floração, promove incrementos na massa seca da raiz, porém não seria benéfico para a parte aérea da planta de tomate, mesmo combinado com outros hormônios como ácido indolbutírico e/ou cinetina.

Verifica-se que, para diâmetro transversal de frutos, as médias dos híbridos foram aumentando conforme se estendia a data da aplicação, começando com $6,7 \mathrm{~cm}$, no controle, até alcançarem $8,3 \mathrm{~cm}$, no $32^{\circ}$ dia (Tabela 3). Além disso, apenas dois híbridos não obtiveram o melhor desempenho nessa última data de aplicação, sendo o H9553, que não se diferenciou do controle e da aplicação no $16^{\circ}$ dia, e o híbrido Caline Ipa-6, cujo melhor desempenho foi no controle e ao $24^{\circ}$ dia. Ressalta-se que os híbridos Saray e HMX 7885 assinalaram valores inferiores no tratamento controle, porém, com a aplicação, os frutos alcançaram valores entre 6 e $9 \mathrm{~cm}$, superiores ao controle, principalmente, no $16^{\circ}$ dia, mesmo com a murcha bacteriana.

De acordo com MARTINS (2013), plantas com moderada quantidade de giberelina apresentam incrementos na sua massa total e no número total de folhas, o que explica o comportamento da maioria dos híbridos testados. Casos como o dos híbridos Acangatã e o Caline Ipa-6, que não apresentaram o mesmo comportamento observado nos outros híbridos, poderiam ocorrer devido à sua alta quantidade de $\mathrm{GA}_{3}$ endógena e, assim, não existe a necessidade da aplicação ou, também, a murcha bacteriana alterou seu balanço hormonal e elevou a quantidade de $\mathrm{GA}_{3}$, impedindo a giberelina exógena de atuar sobre a planta.

Para a variável número de frutos, conforme Tabela 3 , a aplicação no $24^{\circ}$ dia foi a que mais favoreceu o aumento no número médio de frutos, de maneira simultânea para a maioria dos híbridos, com exceção do H9553 e U2006, que foram superiores quando aplicado o $\mathrm{GA}_{3}$ no $16^{\circ}$ e $32^{\circ}$ dia, respectivamente. $\mathrm{O}$ incremento observado para os híbridos BRS Sena e Saray, com a aplicação no $24^{\circ}$ dia, foi de cinco frutos a mais em comparação com o controle.

Já o híbrido H9553 apresentou seis frutos a mais com a aplicação no $16^{\circ}$ dia, indicando que as plantas apresentaram menores níveis de sintomas com a aplicação de $\mathrm{GA}_{3}$, além do aumento no número de frutos, com isso, atrasando o início dos efeitos do patógeno sobre a produtividade.

Observa-se que a média apresentada, pelos híbridos no controle, foi inferior para peso médio do fruto em comparação com os tratamentos com aplicação de $\mathrm{GA}_{3}$, com valores médios superiores e crescentes, conforme se aumentava a data da aplicação (Tabela 3). Os desempenhos superiores foram obtidos pelos híbridos UG 8169 F1, H9553, U2006, Acangatã e U2006, com aproximadamente 15, 40, 34 e 24 g de incremento nas épocas 8, 16, 24 e $32^{\circ}$ dia, respectivamente. Deve-se ressaltar a especificidade da data da aplicação para cada híbrido, como é possível verificar para o híbrido H9553, cuja aplicação feita no $16^{\circ}$ dia fez com que o fruto dobrasse de tamanho se comparado com outras aplicações.

De acordo com os resultados obtidos por DING et al. (2013), o fruto e as variáveis relacionadas aos frutos, como pericarpo, sementes ou até mesmo as células, são dependentes do acúmulo endógeno da giberelina, pois houve aumento significativo da expressão de genes que controlam esse hormônio nas plantas de tomate. Isso poderia indicar a influência do $\mathrm{GA}_{3}$ sobre o fruto e, também, sua manutenção como fruto sadio. Todavia diverge da aplicação do trabalho, pois ocorreu após a antese e em concentrações diferentes da descrita no estudo suprarrelatado. 
Tabela 3. Valores médios de diâmetro transversal do fruto, número de frutos e peso do fruto, com aplicação de giberelina em diferentes épocas de desenvolvimento $\left(0,8,16,24\right.$ e $32^{\circ}$ dias), em híbridos de tomate.

Table 3. Mean values of transverse diameter of the fruit, fruit number and fruit weight, with gibberellin application at different stages of development (0, 8, 16, 24 and $32^{\circ}$ days), in tomato hybrids.

\begin{tabular}{|c|c|c|c|c|c|}
\hline \multicolumn{6}{|c|}{ Diâmetro transversal do fruto $(\mathrm{cm})$} \\
\hline Cultivares & $0^{\circ}$ & $8^{\circ}$ & $16^{\circ}$ & $24^{\circ}$ & $32^{\circ}$ \\
\hline Acangatã & $6,67 \mathrm{cC}$ & $7,33 \mathrm{aB}$ & $7,33 c B$ & $7,00 \mathrm{cC}$ & $8,33 \mathrm{bA}$ \\
\hline BRS Sena & $7,00 c C$ & $6,33 \mathrm{bD}$ & $6,33 \mathrm{dD}$ & $8,00 \mathrm{bB}$ & $8,67 a A$ \\
\hline Heinz 9553 & $8,00 \mathrm{bA}$ & $7,00 \mathrm{aB}$ & 7,67bA & $7,33 c B$ & $8,00 \mathrm{cA}$ \\
\hline HMX 7885 & $3,70 f E$ & $6,33 \mathrm{bD}$ & $7,67 \mathrm{bB}$ & $7,00 \mathrm{cC}$ & $8,67 a A$ \\
\hline Caline IPA 6 & $8,67 a A$ & $6,00 \mathrm{bD}$ & $6,67 \mathrm{dC}$ & $8,67 a A$ & $7,67 \mathrm{cB}$ \\
\hline SARAY & $5,33 \mathrm{eD}$ & $7,67 a B$ & $9,00 \mathrm{aA}$ & $7,00 \mathrm{cC}$ & $9,00 \mathrm{aA}$ \\
\hline U2006 & $6,33 \mathrm{~dB}$ & $7,33 a A$ & $7,33 c A$ & $7,00 \mathrm{cA}$ & $7,67 \mathrm{cA}$ \\
\hline UG $8169 \mathrm{~F} 1$ & $7,67 \mathrm{bB}$ & $6,00 \mathrm{bC}$ & $8,00 \mathrm{bA}$ & $7,33 \mathrm{cB}$ & $8,33 \mathrm{bA}$ \\
\hline Média & 6,67 & 6,75 & 7,50 & 7,42 & 8,29 \\
\hline \multicolumn{6}{|c|}{ Número de frutos (un.) } \\
\hline Cultivares & 0 & $8^{\circ}$ & $16^{\circ}$ & $24^{\circ}$ & $32^{\circ}$ \\
\hline Acangatã & $13,67 \mathrm{bB}$ & $13,00 \mathrm{~dB}$ & $15,67 \mathrm{bA}$ & $15,67 a A$ & $16,33 \mathrm{bA}$ \\
\hline BRS Sena & $10,67 \mathrm{dD}$ & $10,67 \mathrm{eD}$ & $11,67 \mathrm{dC}$ & $15,00 \mathrm{aA}$ & $14,00 \mathrm{~dB}$ \\
\hline H9553 & $11,33 c D$ & $13,67 \mathrm{cC}$ & $17,67 a A$ & $15,00 \mathrm{aB}$ & $15,00 \mathrm{cB}$ \\
\hline HMX 7885 & $10,67 d C$ & $12,33 \mathrm{~dB}$ & $13,00 \mathrm{cA}$ & $13,67 \mathrm{bA}$ & $13,67 \mathrm{dA}$ \\
\hline Caline IPA-6 & $12,00 \mathrm{cA}$ & $10,00 \mathrm{eB}$ & $12,00 \mathrm{dA}$ & $11,67 \mathrm{cA}$ & $10,00 \mathrm{eB}$ \\
\hline SARAY & $10,67 d C$ & $12,67 \mathrm{~dB}$ & $13,67 \mathrm{cB}$ & $15,00 \mathrm{aA}$ & $13,33 \mathrm{~dB}$ \\
\hline U2006 & $14,67 \mathrm{aC}$ & $16,00 \mathrm{aB}$ & $14,00 \mathrm{cC}$ & $15,00 \mathrm{aC}$ & $18,33 \mathrm{aA}$ \\
\hline UG $8169 \mathrm{~F} 1$ & $13,67 \mathrm{bA}$ & $14,67 \mathrm{bA}$ & $13,67 \mathrm{cA}$ & $13,67 \mathrm{bA}$ & $14,00 \mathrm{dA}$ \\
\hline Média & 12,17 & 12,88 & 13,92 & 14,33 & 14,33 \\
\hline \multicolumn{6}{|c|}{ Peso dos frutos $(\mathrm{g})$} \\
\hline Cultivares & 0 & $8^{\circ}$ & $16^{\circ}$ & $24^{\circ}$ & $32^{\circ}$ \\
\hline Acangatã & $33,78 b C$ & $27,09 c D$ & $51,90 \mathrm{cB}$ & $52,90 \mathrm{cB}$ & $75,39 a A$ \\
\hline BRS Sena & $20,32 \mathrm{cD}$ & $30,48 c C$ & $23,89 \mathrm{gD}$ & $60,97 \mathrm{bA}$ & $47,74 \mathrm{cB}$ \\
\hline H9553 & $23,19 c D$ & $39,55 b C$ & $82,88 a A$ & $43,46 \mathrm{dC}$ & $54,04 \mathrm{bB}$ \\
\hline HMX 7885 & $21,72 c C$ & $23,15 d C$ & $34,80 \mathrm{eB}$ & $39,67 d A$ & $44,29 \mathrm{cA}$ \\
\hline Caline IPA-6 & $22,56 \mathrm{cB}$ & $20,00 \mathrm{~dB}$ & $22,21 \mathrm{gB}$ & $31,42 \mathrm{eA}$ & $20,00 \mathrm{~dB}$ \\
\hline SARAY & $21,60 \mathrm{cC}$ & $30,09 c B$ & $30,06 \mathrm{fB}$ & $39,51 \mathrm{dA}$ & $43,70 \mathrm{cA}$ \\
\hline U2006 & $45,18 a D$ & $29,71 \mathrm{cE}$ & $60,87 b C$ & $82,55 \mathrm{aA}$ & $72,55 \mathrm{aB}$ \\
\hline UG $8169 \mathrm{~F} 1$ & $24,50 \mathrm{cC}$ & $45,54 a A$ & $40,66 \mathrm{dA}$ & $35,22 \mathrm{eB}$ & $44,17 \mathrm{cA}$ \\
\hline Média & 26,60 & 30,70 & 43,41 & 48,21 & 50,24 \\
\hline
\end{tabular}

Médias seguidas pela mesma letra minúscula na vertical e maiúscula na coluna, não diferem entre si pelo teste de Scott-Knott (5\%).

$\mathrm{A} \mathrm{GA}_{3}$ apresenta efeitos benéficos além do aumento das variáveis supracitadas, indicando que as plantas de tomate podem apresentar aumento na tolerância a doenças, via aplicação desse hormônio. Nos estudos de DING et al. (2015), frutos de tomate-cereja revelaram menor dano quando refrigerados a frio, se aplicado ácido giberélico nos frutos. Os resultados demonstraram, também, que, quando os frutos foram tratados por paclobutrazol, neste caso, utilizado como inibidor de biossíntese da giberelina, as lesões foram bem superiores.

Com base nos resultados e no comportamento dos híbridos de tomate, infere-se que as plantas apresentaram aumento na tolerância à murcha bacteriana. Porém, pesquisas futuras devem avaliar o efeito da $\mathrm{GA}_{3}$ sobre as plantas, com e sem infecção, como forma de identificação dos possíveis mecanismo de proteção ou, possivelmente, a campo para alcançar conclusões mais amplas e com novas épocas de aplicações e/ou doses. 


\section{CONCLUSÃO}

A giberelina é capaz de induzir o aumento da tolerância em plantas de tomate à murcha-bacteriana (Ralstonia solanacearum), entretanto a época de aplicação é dependente do híbrido e da variável.

A aplicação feita no $24^{\circ}$ dia, após a semeadura, foi a que propiciou mais benefícios aos diferentes híbridos e, à maioria das variáveis, simultaneamente, àquela do $32^{\circ}$ dia, sendo esses procedimentos os mais indicados para tomates visando ao aumento da tolerância à murcha bacteriana .

\section{REFERÊNCIAS}

AYANA G \& FININSA C. 2016. Effect of crop rotation on tomato bacterial wilt (Ralstonia solanacearum) and survival of the pathogen in the rhizospheres and roots of different crops in Ethiopia. International Journal of Phytopathology 5: 8188.

AYUB RA \& REZENDE BLA. 2010. Contribuição do ácido giberélico no tamanho de frutos do tomateiro. Biotemas 23: 25-28.

CATO SC et al. 2013. Sinergism among auxins, gibberellins and cytokinins in tomato cv. Micro-Tom. Horticultura Brasileira 31: 549-553.

DING $J$ et al. 2013. Cytokinin-induced parthenocarpic fruit development in tomato is partly dependent on enhanced gibberellin and auxin biosynthesis. PLoS One 8: e70080.

DING Y et al. 2015. The role of gibberellins in the mitigation of chilling injury in cherry tomato (Solanum lycopersicum L.) fruit. Postharvest Biology and Technology 101: 88-95.

FARINHA TB. 2008. Envolvimento da giberelina na regulação do desenvolvimento vegetativo e reprodutivo de tomateiro (Solanum lycopersicum) cv Micro-Tom. Dissertação (Mestrado em Fisiologia e Bioquímica de Plantas). Piracicaba: ESALQ. 73p.

FERREIRA DF. 2011. Sisvar: a computer statistical analysis system. Ciência e Agrotecnologia 35: 1039-1042.

JIANG $\mathrm{J}$ et al. 2014. Effect of seed treatment by cold plasma on the resistance of tomato to Ralstonia solanacearum (bacterial wilt). Plos one 9: e97753.

LOPES CA \& ÁVILA AC. 2005. Doenças do tomateiro. Brasília: Embrapa Hortaliças. 151p.

LOPES CA et al. 2015. Eficácia relativa de porta-enxertos comerciais de tomateiro no controle da murchabacteriana. Horticultura Brasileira 33: 125-130.

MARTÍNEZ LO et al. 2013. Efecto de las giberelinas sobre el crecimiento y calidad de plántulas de tomate. Biotecnia 15: 56-60.

MARTINS AO. 2013. Impactos ecofisiológicos e metabólicos da alteração nos níveis de giberelina em tomate. Dissertação (Mestrado em Fisiologia). Viçosa: UFV. $95 f$.

MORAIS TP et al. 2015. Occurrence and diversity of Ralstonia solanacearum populations in Brazil. Bioscience Journal 31: $1722-1737$.

ROCHA DJA \& MOURA AB. 2013. Controle biológico da murcha de tomateiro causada por Ralstonia solanacearum e Fusarium oxysporum f. sp. licopersici por rizobactérias. Tropical Plant Pathology 38: 423-430.

Rodrigues LMR et al. 2011. Pathogenicity of Brazilian strains of Ralstonia solanacearum in Strelitzia reginae seedlings. Tropical Plant Pathology 36: 409-413.

TAIZ L \& ZEIGER E. 2013. Fisiologia vegetal. 5.ed. Porto Alegre: Artmed. 954p.

TAKATSU A \& LOPES CA. 1997. Murcha-bacteriana em hortaliças: avanços científicos e perspectivas de controle. Horticultura Brasileira 15: 170-177. (Suplemento).

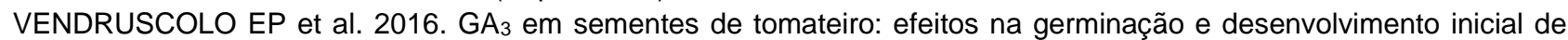
mudas. Revista de agricultura neotropical 3: 19-23. 